\title{
Pre-service Elementary Generalist Teachers' Past Experiences in Elementary Physical Education and Influence of these Experiences on Current Beliefs
}

\author{
Lynn Randall \\ University of New Brunswick \\ Julienne K. Maeda \\ University of Hawai $i$ at Manoa
}

\begin{abstract}
A lack of formal training in physical education leave pre-service generalist teachers little choice but to remember their past experiences for lesson ideas. Past experiences as elementary students may shape what and how pre-service generalists will teach. This study explored the past experiences of pre-service generalists teachers and the extent those experiences shape what they see as the purposes for elementary physical education. Findings indicate past experiences can influence current views. The implications for teacher education are discussed.
\end{abstract}

Keywords: elementary generalist teachers, physical education, teacher beliefs, past experiences

Lynn Randall is an associate professor in the Faculty of Education at the University of New Brunswick.

Email: 1randall@unb.ca

Julienne Maeda is currently an associate professor and department chair in the College of Education at the University of Hawai $i$ at Manoa.

Email: julienne@hawaii.edu

Brock University, Volume 19, No. 2, Spring 2010, 20-35 


\section{Pre-service Elementary Generalist Teachers' Past Experiences in Elementary Physical Education and Influence of these Experiences on Current Beliefs}

Elementary physical education has undergone a number of changes in recent years due in large part to financial constraints, the marginalized status of physical education by government and school officials, and lack of qualified personnel (Hardman \& Marshall, 2000). More specifically, specialists in elementary physical education are not readily hired and more generalist teachers are responsible for teaching physical education (Active Healthy Kids Canada, 2009; Cameron, Wolfe, \& Craig, 2007; NASPE \& AHA, 2006). This is often very difficult for generalists as they have little background in formal movement training. In teacher education programs the requirements range from no requirement to one required three credit hour methods and/or content course, or left as an elective (Ashy \& Humphries, 2002; Faucette \& Patterson, 1989). This is problematic because more generalists are teaching a subject area in which they are often ill prepared (DeCorby, Halas, Dixon, Wintrup, \& Janzen, 2005; Morgan \& Hansen, 2008). Hours of planning and in-service sessions may help to overcome this shortcoming (Faucette, Nugent, Sallis, \& McKenzie, 2002) but such programs are not always available. Also, when provincial, regional, or government testing requirements focus on subjects such as math, language arts, and science, the classroom teacher is more likely to spend his/her limited planning time in the content areas for which there is more public accountability. With limited time available for physical education planning, and limited background knowledge in the subject area (DeCorby et al., 2005), the generalist teacher often has little choice but to attempt to recall his/her own past memories and personal experiences in physical education classes for lesson ideas (Barney \& Deutsch, 2009).

Past experiences shape teachers' beliefs about teaching, influence what they teach, how they teach, and what they believe their future students should know and be able to do (Pajares, 1992; Ryan, Bridges \& Yerg, 2000). Pre-service teachers' beliefs about teaching and what teachers do are formulated several years before they even begin a teacher education program. From the moment students enter a classroom around the age of five, they begin a process known as 'professional socialization' (Pooley, 1975). Professional socialization refers to "the process whereby the recruit comes to learn about and internalize the culture of the profession he [sic] has elected to enter" (Pooley, 1975, p. 99). This period of time is also referred to as anticipatory socialization (Burlingame, 1972), the apprenticeship of observation (Lortie, 1975), recruitment (Dewar, 1989), and pre-training (Zeichner \& Gore, 1990).

Research examining the beliefs and socialization of pre-service teachers has been conducted in physical education teacher education for the past three decades. Early research found that a custodial orientation toward teaching is often present in that physical education majors are more likely to reproduce and preserve the physical education programs they experienced rather than attempt to change or transform them (Lawson, 1983). Later research found that physical education majors have established, well formed beliefs about teaching and teaching physical education (Doolittle, Dodds, \& Placek, 1993; Placek, Dodds, Doolittle, Portman, Ratliffe, \& Pinkman, 1995) and tend to select teaching physical education as a career choice based on past experiences (Hutchinson,1993). More recently, these findings have been confirmed (Stran \& Curtner-Smith, 2009).

The literature is replete with information regarding the beliefs about physical education held by pre-service teachers majoring in physical education; however little is known about the physical education beliefs held by pre-service generalist teachers. The importance of examining 
the beliefs and prior experiences of future teachers is important (Barney \& Pleban, 2006; Morgan $\&$ Bourke, 2008) because prior beliefs and experiences appear to strongly influence and perpetuate the reproduction of traditional programs, sidelining or negating the potential positive influence that teacher education programs can provide (Ashy \& Humphries, 2000; CurtnerSmith, 2007, Xiang, Lowy, \& McBride, 2002). It could be hypothesized that pre-service generalists would also hold a similar custodial orientation of physical education. Indeed, with the number of generalist teachers expected to teach physical education it would not be surprising to learn that many of them base their perceptions of physical education on past experiences. Such perceptions can influence what they see as the purpose for physical education which can impact how they teach the subject. To that end, researchers have begun to more deeply explore preservice generalists' attitudes toward, and beliefs about, the purposes of physical education (Morgan, 2008; Ryan, Bridges, \&Yerg, 2000).

Research (Randall \& Maeda, 2003) has found that many pre-service generalist teachers reported having both positive and negative physical education experiences. When asked to recall past elementary physical education experiences, a number of participants vividly recalled fitness testing where only a select few excelled and enjoyed the experience, while a greater number failed and were publicly embarrassed by their performance. Few recalled any "teaching" but plenty of "playing". Hence the continued perception by many that no learning occurs in physical education. Other researchers (Ashy \& Humphries, 2000; Hart, 2005; Weinberg, Petrillo, Doering, Lund, \& Rowe, 2000; Xiang, Lowy, \& McBride, 2002) have examined the effects of an elementary physical education methods course on attitudes and beliefs about teaching physical education. All of the studies reported the effectiveness of one elementary methods course. Findings include, but are not limited to: raising knowledge of skills, heightened awareness about its importance, more appreciation for the demands of teaching physical education, and positively changing initial attitudes toward physical education. Concomitantly, though awareness for the importance and demands of teaching physical education were increased, participants were still hesitant in their willingness to teach physical education (Morgan, 2008; Morgan \& Bourke, 2008; Xiang, et. al., 2002). Participants reported that they had no personal interest in physical education, felt incompetent and not confident about teaching good lessons, and considered the physical education environment to be undesirable. Faucette and Patterson, (1989) and Morgan and Hansen (2008) found similar findings in their research with in-service generalist teachers.

Though one methods course in elementary physical education can positively affect how pre-service generalist teachers view physical education, the influence of past experiences on current beliefs about the purposes of physical education has not yet been examined. Physical education (Doolittle, Dodds, \& Placek, 1993; Hutchinson, 1993; Morgan \& Bourke, 2008; Morgan \& Hansen, 2008; Placek et al., 1995; Stran \& Curtner-Smith, 2009) and general education (Feiman-Nemser, 1983; Leavy, McSorley, \& Bote, 2007; Pajares,1992) researchers have reported that past experiences can influence pre-service teachers' beliefs' about subjects and teaching that subject, act as filters for all incoming information, and are difficult to change. Thus, the purpose of this study was to describe the past physical education experiences of preservice generalists teachers and the extent to which those experiences shape what they see as purposes for elementary physical education. Findings from this study may contribute to more effective use of limited instructional time by considering the current beliefs about the purposes of teaching elementary physical education held by pre-service generalist teachers, and attempting to replace or eradicate misconceptions. 


\section{Methods}

\section{Participants and Settings}

Participants $(\mathrm{N}=54)$ were from two classes of elementary education pre-service teachers enrolled in a required three-credit physical education methods class (28 students in one class; 26 students in the second class). The course was the only exposure to physical education content and pedagogy pre-service generalist teachers would receive. It was specifically intended for generalist teachers and as such, the course was an introduction to both the content and basic pedagogical practices of elementary physical education. The degree students were completing at the time was a post-degree, two-year Bachelor of Education program offered at a university in Eastern Canada. Ethics approval from the university research ethics committee was received. Informed consent was received from all 54 participants ( 13 males and 41 females). Participants ranged in age from 20-38 years. The mean age of the males was 26.25 years with a range of 22 to 38 years. All males were Caucasian. The mean age of the females was 24.58 years with a range of 20 to 43 years. One female was Asian and the remaining Caucasian.

On the first day of class, the instructor, also one of the study's researchers, informed the participants of the study. Also in the room during this discussion was another instructor. This second instructor was a secondary methods instructor whom participants in the class would never meet in the program. After a description of the study was provided, participants were encouraged to ask questions about the study and were assured that their acceptance or refusal to participate would in no way affect their grade as the instructor would be unaware of who agreed to participate until after all grades were submitted. They were also informed they could withdraw their consent for use of their data in the study at any time simply by contacting the appropriate secretary. Once there were no further questions, the researcher left the room, and the second instructor passed out the informed consent forms. Students had another opportunity to ask questions with the researcher absent. According to the instructor in the room, no questions were asked. After students read the consent form one student collected the forms, sealed them in an envelope and gave them to the Associate Dean of undergraduate students' secretary. This is the person whom faculty submit their grades at the end of term. At the completion of the term, when the instructor handed in the final grades for the course, the secretary provided the researcher with the consent forms. All students had signed the consent forms (100\% participation).

\section{Data Sources and Analyses}

As part of their regular course work, class participants were required to complete the 'Personal Reflections of PE' questionnaire which was an assignment that asked participants to recall and reflect upon their past experiences with physical education and their concerns with having to teach physical education in the future. The questions had been pilot tested with two groups of similar students the previous year. Participants were first asked,

In the very near future, you will be responsible for teaching physical education to your students. What do you believe is/are the most important purposes of elementary physical education? That is, what do you think should be taught or what do you want your students to learn?

Once all participants had answered the question, they were then provided with a series of questions that asked them to recall their past K-12 physical education experiences. For example, 
the first question asked participants to clearly explain and provide examples of their own elementary physical education experiences. They were asked to specify what stood out, who taught physical education, frequency and length of classes and if they were taught skills. Statements about feelings they had about their performance in relation to their peers were also requested. Participants were provided class time and were encouraged to talk with classmates to facilitate recall. Following informal, in-class discussion with classmates, participants were then given a week to provide detailed written answers to the questions. Pilot work revealed that the longer students had to respond, the more likely it was that class content influenced their answers. For example, during pilot work, the researches noticed that following a discussion on appropriate games at the elementary level, participants' comments mirrored statements found in readings and those provided in class. The one-week turnaround time was short enough to minimize the effect course content had on their memories and beliefs but long enough to allow for enough reflection to provide complete and detailed written answers.

Since the assignment was a course requirement, students were required to submit their work within one week of the first day of class. After an initial read and check of their work (graded as complete or incomplete) the assignments were returned and where necessary, students were asked to clarify or provide more complete responses, and re-submit. Following this, the instructor presented the commonalities and differences amongst the assignments. The content from this discussion served as an introduction to a number of course topics, for example, appropriate practices. Since it was unknown to the researcher which students had previously provided consent, these discussions could not be used as data but they did help inform the data during analysis.

After final grades were submitted, both researchers formally reviewed all of the data. Inductive analysis and constant comparison (Lincoln \& Guba, 1985) were used to analyze the data. Initially one participant's data set was read multiple times by both researchers independently. At this point, the researchers independently began to identify key phrases, sentences and ideas. A discussion was held where the researchers would share their initial thoughts and findings. Loose categories of ideas were initially created. The same procedure was carried out with two more data sets. With each additional data set, the researchers began to further develop their categories and began to talk about recurring themes that were emerging. As more and more data sets were reviewed, the data were constantly compared between the emerging categories and themes. Throughout the process, categories were expanded and others were modified. After this initial process was complete, a lengthy discussion ensued whereby the researchers semi-finalized their themes and the categories of which each was comprised. Then an additional independent reading of the data occurred, the intent of which was to ensure the themes were representative of the data. This continued until the researchers were satisfied that the categories and ideas contained within them, reflected the data.

Other categories specifically developed included number of physical education classes per week, the length of class, whether participants were taught by a generalist or specialist teacher, type of assessment, and enjoyment of class.

\section{Findings}

The findings are based on the written responses provided by the participants. This section is divided into five themes: a) background experiences, b) memories of enjoyment, c) past 
experiences, d) current beliefs about the purposes of elementary physical education, and e) influence of past experiences on current beliefs.

\section{Background Experiences}

The majority $(72 \%)$ of participants in this study had a physical education specialist during their elementary school experiences. Most of the participants (95\%) also reported having had regularly scheduled physical education classes. Classes ranged from once a week for 20 minutes to 3-4 times a week for 40 minutes. In describing why her classes were not held regularly, one participant stated, "I remember that if we were not quiet or did not lineup at the door correctly, our class was quickly taken away and we would do more math". As another participant described:

I remember in elementary school, a specialist in the gymnasium taught us. All of our classes were co-ed for the most part. We covered units on: health, nutrition, stretching, gymnastics and the usual sports such as badminton, soccer, basketball, kick ball and obstacle courses. Phys.ed classes took place in the school gym and usually happened on odd or even days (3-4 times a week for about 40min).

\section{Memories of Enjoyment}

During the elementary years, many participants expressed having enjoyed physical education regardless of their level of competence. Below are two quotes representative of those participants who enjoyed their earlier experiences:

Throughout my elementary years I enjoyed gym class for the most part. I was not the "sportiest" but I did participate a lot and enjoy myself. I guess I would have been about average in relation to others in my classes.

Another student offered the following memory of enjoying elementary physical education: I remember having Phys Ed practically everyday, either in the form of games, gymnastics, square dancing. It was more like organized play or a good way to release energy. I always thought it was fun and a good break from the regular sit down activities of school. I did not consider myself one of the most physically agile students in the class as I was small and younger than most.

Although many participants recalled positive experiences, there were some students who shared some negative memories. What was interesting was that written descriptions of their memories of the negative experiences were much more detailed and appeared more reflective in nature than those provided when participants shared their positive experiences. A male participant provided the following comment:

When I think of my elementary years, with physical education in particular, I remember a game of musical chairs. There were two of us competing for one chair, when the music went off, I lost. The class claps and cheers. I was raised not to "to push or to hit". I was taught not to be aggressive, and I find that sports require aggression. I was taught not to feel pride over another's loss. I sucked in Physical education. Sports takes aggressive people who do not mind winning over someone else's loss. As you have probably guessed by now, I did not like the competitive nature of physical education very much. But the ironic thing is, that, when I got home, some friends and I would play the same sports, baseball, hockey, soccer, tag, without all the pressure of winning and I enjoyed it. Don't 
get me wrong, we enjoyed winning, but the pressure was not the same. We did not have the embarrassing moments of ridicule in a public forum. There were laughs and chuckles, and some embarrassing moments, but it was fun. We were not led by a coach scouting for skilled players for his/her team. Other than that I do not remember much about physical education.

The participants' memories of their past physical education experiences ranged from positive to negative in relation to the extent to which they enjoyed their classes. The negative or positive experiences were independent of perceived ability.

\section{Past Experiences}

Four main categories of experiences emerged from the participants' responses to questions about their past experiences. These included, play, skill learning, fitness and break. A frequency table of responses can be found in Table 1 .

The largest category by far was the Play category. Here participants listed a number of games or activities they played, or wrote about playing various games with no indication that any instruction occurred. In one example:

Thinking back to my elementary experiences, I have to admit that I don't remember a lot, it's been a long time. But I do recall enjoying going to the gym. I liked my teachers and the chance to play. Phys. Ed. felt more like playing than anything. For example, we played tag and had a lot of free time to play whatever we chose. So it was more like a recess than a class.

The category Skill Learning includes comments where students specifically stated they were taught skills. The following are two examples of comments that fell into this category:

It was probably grades four-six before the teacher introduced basketball, baseball, volleyball and badminton. I remember learning to dribble the basketball and kick the soccer ball. We learned how to dribble in one spot, while moving, with our eyes on the ball and then away from the ball. When we actually tried to play a game of basketball, I always found it really hard and I never really enjoyed it. I think on it now and realize I probably had to concentrate on too many things happening in the game concurrently that were never practiced.

Another student recalled:

I remember learning various skills e.g., basketball-learning how to dribble; badmintonlearning the handshake. I use to like to play badminton. I hated going over the serve, because I couldn't serve properly. But I remember her encouraging to serve the proper way.

The Fitness category includes comments that specifically talked about fitness testing or fitness related activities. A number of participants reported participating in the Canada Fitness test. For example, one participant stated, "A big thing that stands out is attempting to complete those physical activity charts with the different tasks, and classifications depending on your outcomes in each event (gold, silver, bronze,)." Other participants recalled negative memories related to the same event, for example, "We would have to participate in Canada Fitness once a year, which I thought was awful because if you did not get a gold or an excellent everyone knew and it was embarrassing."

There were several comments that related to physical education being about a 'break' from the regular day for another recess. The comment made by the following participant is a 
representative example of the types of comments that can be found in this category: "My overriding impression of elementary school physical education was that it was an extension of recess where the girls played skip and elastics (no teacher needed) while the boys played baseball."

\section{Current Beliefs of the Purposes of Physical Education}

Current beliefs at the elementary level were investigated as this would be the level at which these participants would be teaching upon graduation from their teacher education program.

Participants were asked a series of questions that probed what they believed were the most important outcomes for elementary physical education. Here five categories emerged. These were, social learning, lifetime activity, skill learning, safety, and enjoyment. A frequency table of responses can be found in Table 1 .

Table 1

Past and Current Beliefs About the Purposes of Physical Education

$\begin{aligned} & \text { Past } \\
& \text { Experiences }\end{aligned}$
\begin{tabular}{|l|l|l|l|}
\hline Category & Frequency & Category & Frequency \\
\hline & & & \\
Play & 78 & Social Learning & 85 \\
Skill Learning & 20 & Lifetime Activity & 40 \\
Physical & 20 & Skill Learning & 26 \\
Fitness & 5 & Enjoyment & 16 \\
Break & 5 & Safety & 7 \\
& & & \\
\hline
\end{tabular}

\section{Social Learning}

The largest category was the social learning category. Included in the 'social learning' category were statements that expressed the importance of encouraging students, teaching them to work together, and teaching respect for one another. A representative example of statements that were included in this category follows:

I think that some of the basic things that I would want to teach would be positive attitudes towards exercise and learning, cooperation with others, and a sense of fair play. I think that building self-confidence, self-esteem, providing opportunities for exercise and to learn new skills are some of the main goals of physical education instruction. I think that promoting a positive attitude and helping to build self-esteem are important because I always had a low self-esteem...I really think that good sportsmanship (the ability to work with others and a good sense of fair play) is something that should be instructed 
throughout all grades. I think that as students get older it is important to emphasize this area to help make students feel comfortable regardless of their skill level.

\section{Lifetime Activity}

When recalling their past experiences many participants recalled memories about fitness testing, hence the category discussed in the previous section. Yet, when thinking about the future, participants never mentioned incorporating fitness testing into their lessons but rather about preparing students for a lifetime of activity. Thus, 'lifetime activity' is a broad category that includes fitness, not in the sense of a test, but as it relates to overall health and a lifetime of healthy activity. The following two quotes are examples of statements found in this category: Physical education has the potential to have a huge impact on people and how they decide to live their lives. For example, if a child is taught about the importance of physical activity and informed on the different ways of staying physically fit, this attitude will carry over outside of school and this child will grow up to be healthier and happier than a person who may not practice physical fitness.

Similarly, another student stated:

It is a concern that all of my students live an active and happy lifestyle. In order for this to happen, I need to make my students aware of the benefits and how to maintain an active life. If more people are physically fit, it not only has an effect on that one individual, but also on everyone around them.

\section{Skill Learning}

A number of participants provided comments that specifically addressed the teaching of skills. Thus the category 'skill learning' is similar to the category in past experiences and its emergence under current beliefs suggests participants believed that skill development is an important part of physical education. The quote below is representative of the types of comments found in this category:

For the most part, I would like to focus on building up solid skills (dribbling, throwing, catching, running, etc) with the children, as opposed to teaching them a little bit and then putting them in a game. I think that having solid skills in sports and a good knowledge of the rules is important because, if some kids don't get it now, it's only going to get worse for them later on in their physical education classes.

\section{Safety}

A fourth category was labeled 'safety'. A number of participants were thinking ahead about their future students' safety. A number of participants included comments related to building a knowledge base related to correct ways to move and how to carry out activities safely. The following is an example of the types of responses found in this category:

The correct way to move (exercise) without doing damage to the body and the rules of the games. I do not want to get students to do activities that they will hurt themselves doing because they are doing them wrong. By knowing the rules then you can ensure that they start off knowing what they can do so that they can then build on these to better their game.

\section{Enjoyment}


The final category was labeled 'enjoyment'. This remained a separate category from social learning because there were so many comments that related specifically to the idea that physical education classes should be fun and enjoyable. Fun and enjoyable from participants' perspectives suggested that the learning process was fun; it made learning skills and new activities fun.

The goals I would like to accomplish with my students would be for them to find pleasure in variety and trying new things. I think that a game should focus on skills development such as teamwork, good sportsmanship and motor skills however they should also be enjoyable for the student.

Another student stated:

We have responsibilities as a teacher to teach the students what is in the curriculum document, regardless if we think it is the right or wrong way. BUT, it is our duty to make it enjoyable for the students so that we do not make physical education a bad experience for them.

\section{Influence of Past Experiences on Current Beliefs}

One of the most striking findings to emerge from the data was the degree to which participants' linked their past experiences to their current beliefs. Repeatedly, participants would make mention of what they thought was important to teach in a physical education class and justify their decision based on experiences they remembered from the past. For example one participant stated, "When I would teach a sport I would make sure everyone understood the rules and go over the skills numerous times. I did not do that much in elementary school. We just basically played the games." Similarly, another participant provided a detailed rationale that clearly illustrated the feelings and sentiments of others. After describing a number of past experiences, he concluded with the following:

If I am teaching physical education, I will try not to repeat the past mistakes of my gym teachers. I want to make all my students feel that they can accomplish something if they keep at it. They may never be the best, but they will improve with practice. This was an important lesson that took me ten years of gym class to figure out. I want to teach my students perseverance and teamwork. I want them to understand that it takes patience to get to where they want to be, and this message stands up anywhere, whether it is on the basketball court or the real world.

Through the reflective writing assignment, participants were able to recall and describe their previous experiences in physical education classes. It became clear that their personal memories influenced what they believed were the purposes of elementary physical education.

Participants' physical education experiences were both varied and similar. They are varied in that some had specialists and some did not; some had positive experiences while others were negative; some had structured learning programs whereas others described their programs as another recess or a free play period. They are similar in that they believe that physical education classes are about social learning, lifetime activities, skill learning, safety and enjoyment. Their beliefs about what a physical education program should be about is based largely on their past experiences as students in public school physical education classes.

\section{Discussion}


The results from this study suggest that the past experiences and previous beliefs of physical education by pre-service generalist teachers are not vastly different than pre-service physical education specialists (Morgan \& Bourke, 2008; Placek, et al., 1995; Ryan, Bridges, \& Yerg, 2000). Participants who distinctly remember having a specialist teacher recalled more regular classes with more of an emphasis on learning skills. On the other hand, it is interesting to note the impact the teacher has on student's enjoyment and feelings of competence. It is nothing new to note the effect the teacher has on student learning and engagement. The voices of the participants here simply confirm that the teacher, the way he/she acts and talks to students, the way he/she selects and organizes content, and the way he/she treats students can impact students' perceptions and experiences in physical education. Furthermore, the participants' comments about their experiences (e.g., "sexist", "too competitive", "scared of the teacher", "singled out", "wasn't put on display", "my teacher was very fair and clear on his expectations") highlight the variety of environments that were present in their physical education experiences and its lasting effect on their memories. These memories have remained with them for nearly two decades.

Relative to past beliefs, the 'play' category contained the most entries. This may have been because some participants were not sure or could not remember if they were taught skills in their early elementary years. Their memories seemed to become clearer as they thought about classes in the higher elementary grades, at which point many distinctly remembered being taught skills. With the majority of participants in this study having had a specialist at the elementary level, this finding may correspond to the idea of building a foundation for movement in the early elementary years. The instruction and delivery of skill learning early on in elementary school is to help children understand the concepts and skills necessary for later specific sport or physical activity use (Graham, Holt/Hale, \& Parker, 2010). More sport-related instruction tends to occur in the higher elementary grades. Further, developmentally appropriate practice relative to teaching suggests motor skills be taught to younger children through less direct teaching methods (Pica, 2010) which for children learning to jump rope, dribble, or skip may resemble play and not learning skills. For older children, instruction tends to be much more explicit and with more sport-specific skills being taught, this may have changed the way the participants viewed physical education.

Interestingly, the 'play' category did not exist when participants began discussing what they saw as the purposes of their future programs. This is an extremely encouraging finding and one that differs from previous studies (Placek, et al., 1995; Ryan et al., 2000; Xiang, et al., 2002). It appears that the perception of physical education as play may be changing, at least for this group of future elementary generalist teachers. It is encouraging that these participants, who are training to be elementary teachers, appear, at this point in their careers, to view physical education as a subject area with broader, educational outcomes other than simply another free play period.

For these participants, the influence of past experiences appears to also have influenced their current beliefs of the purposes for physical education. Participants' current beliefs toward the purposes of elementary physical education were surprising when compared against their past beliefs. The top category to emerge that participants cited as being what they believed to be the purpose of elementary physical education was social learning. In recalling past experiences, no references were found to this category yet, as a current purpose, many participants mentioned it as an important aspect of physical education. Participants believed that elementary physical education should, "teach them [children] teamwork, how to play fair," and "PE teachers should be teaching students how to play well with one another, not vindictively to simply be the best." 
A possible explanation for the difference is that upon reflection, many participants of all skill levels recalled either feeling embarrassed or left out at times, or commented that 'although I was never picked last, it must have been awful for them'. Thinking to the future, the participants recognized that what they experienced was not necessarily the atmosphere they want to create and hence the focus on creating a more welcoming environment for all; an environment that begins with respect for self and others.

The skill learning category was the only category present in both past and current beliefs. This is an encouraging finding as students appear to recognize the importance of teaching skills in elementary physical education. Researchers (DeCorby et al., 2005; Faucette \& Patterson, 1989; Morgan, 2008) have commented that generalists are ill-prepared for teaching physical education and often feel uncomfortable teaching this content. However, knowledge of skill and more confidence in teaching this subject area can be provided to generalists through a methods class (Hart, 2005; Morgan \& Bourke, 2008; Xiang et al., 2002). Still, as a marginalized subject area, it is not unusual for little planning to go into lessons. In such cases teachers may rely on their memories of past experiences when planning or putting together a lesson. For these participants, though their play memories were strong many did recall being taught skills and many commented that they believed skill learning to be important. Again, their memories tended to be clearer in their later years of elementary school, typically around the time children learn more sport-specific skills. Perhaps the teaching of sport-specific skills tends to be covered in middle and high school and is more visible in the media so maybe they are easier for generalist teachers to grasp and teach due to their clear connection to sports. This finding could be attributed to the fact that the majority of participants had a specialist for elementary physical education. What remains unknown is whether their past play experiences are stronger than their desire or knowledge to teach skills in the future.

Participants' memories of fitness being so focused on a test are discouraging. However, the memories, most of which were negative, were likely to have a positive effect in these participants' future teaching. Participants saw the importance of fitness as a lifetime activity and have intentions to teach their students accordingly. Their past memories definitely influenced their desire not to repeat such practices with their future students. But also of influence here may be the larger social climate that currently exists. With news of increasing obesity rates and lack of activity regularly being reported in the news, on posters around campus, etc., perhaps students see the need to tackle the issue in their future classes.

A category that has not appeared in other studies but did appear here relates to 'safety'. Many of the safety related comments were the result of participants recognizing their lack of knowledge and ability with respect to physical education content. Participants recognized this as a limitation and something they would have to work at improving.

It is not surprising to see 'enjoyment' as a separate category. It is surprising to note that enjoyment was not limited to participation only; that is, physical education as fun. For these participants, student 'learning' and 'achievement' contributed to an enjoyable experience. This is in contrast to previous research (Placek, et al., 1995; Xiang, et al., 2002) where entries in similar categories focused on fun as an outcome as opposed to this study where fun was a by-product of learning and being successful. Comments that often made it into this category used 'enjoyment' in conjunction with activity. That is, skill learning can be fun; fitness can be enjoyable. For those with negative past memories, this was particularly important. For these participants they did not want their future students to have similar negative experiences. For students with positive memories, they wanted their students to have similar positive experiences. Again, this 
demonstrates that past memories do influence current beliefs whether these experiences were positive or negative.

With more generalist teachers teaching at the elementary level the importance of a minimum of one required elementary physical education methods class during teacher preparation becomes even more necessary. Future studies should continue to investigate the effect of past experiences on both the beliefs of pre-service generalist teachers and the degree to which their beliefs translate into practice.

\section{Conclusion}

The results of this research clearly indicate that past experiences influence what preservice generalist teachers see as the purposes for elementary physical education. Their intentions for their future students are strongly based on their past experiences and their desire to replicate positive experiences and modify and change negative ones. Physical education pedagogues must acknowledge and investigate these experiences because if left unexplored, future elementary generalist teachers may continue to replicate misguided practice. By examining the beliefs of their students, teacher educators can best decide how to effectively use their limited contact time with their students to develop and present content that is most meaningful and relevant to the students and also aligns with what the teacher educator expects students to know and be able to do. 


\section{References}

Active Healthy Kids Canada (2009). The Active Healthy Kids Canada Report Card on Physical Activity for Children and Youth. Toronto, Ontario, Canada.

Ashy, M., \& Humphries, C. A. (2000). "Don't use balloons on windy days": Elementary education majors' perceptions of teaching physical education. Action in Teacher Education, 22(1), 59-71.

Barney, D., \& Deutsch, J. (2009). Elementary classroom attitudes and perspectives of elementary physical education. (Report). Physical Educator, 66, 114-123.

Barney, D., \& Pleban, F. (2006). Pre-service physical education teacher's perceptions of teaching before and after a semester long elementary physical education practicum experience. Physical Educator, 63, 46-52.

Burlingame, M. (1972). Socialization construct and the teaching of teachers. Quest, 18, 40-56.

Cameron, C., Wolfe, R., \& Craig, C.L. (2007). Opportunities for physical activity in Canadian schools: Trends from 2001-2006. Ottawa, Ontario, Canada: Canadian Fitness and Lifestyle Research Institute.

Curtner-Smith, M. D. (2007). The impact of a critically oriented physical education teacher education course on preservice classroom teachers. Journal of Teaching in Physical Education, 26, 35-56.

DeCorby, K., Halas, J., Dixon, S., Wintrup, L. \& Janzen, H. (2005) Classroom teachers and the challenges of delivering quality physical education, Journal of Educational Research, 98(4), 208-220.

Dewar, A. M. (1989). Recruitment into physical education teaching toward a critical approach. In T. Templin \& P. Schempp (Eds.), Socialization into physical education: Learning to teach (pp. 39-58). Indianapolis: Benchmark Books.

Doolittle, S. A., Dodds, P., \& Placek, J. H. (1993). Persistence of beliefs about teaching during formal training of preservice teachers. Journal of Teaching in Physical Education, 12, $355-365$.

Faucette, N., Nugent, P., Sallis, J. F., \& McKenzie, T. L. (2002). “I'd rather chew on aluminum foil." Overcoming classroom teachers' resistance to teaching physical education. Journal of Teaching in Physical Education, 21, 267-286.

Faucette, N., \& Patterson, P. (1989). Classroom teachers and physical education: What they are doing and how they feel about it. Education, 110, 108-114.

Feiman-Nemser, S. (1983). Learning to teach. In L. Shulman \& G. Sykes (Eds.), Handbook of teaching and policy (pp. 150-170). New York: Longman. 
Graham, G., Holt/Hale, S., \& Parker, M. (2010). Children moving. A reflective approach to teaching physical education. ( $8^{\text {th }}$ ed.). NY: McGraw-Hill.

Hardman, K., \& Marshall, J. J. (2000). Physical education in schools: Preliminary findings of a worldwide survey. Part II. International Council for Health, Physical Education, Recreation, Sport and Dance, 36(4), 8-12.

Hart, M. (2005). Influence of a physical education methods course on elementary education majors' knowledge of fundamental movement skills. Physical Educator, 62, 198-204.

Hutchinson, G. E. (1993). Prospective teachers' perspectives on teaching physical education: An interview study on the recruitment phase of teachers' socialization. Journal of Teaching Physical Education, 12, 344-354.

Lawson, H. A. (1983). Toward a model of teacher socialization in physical education: The subjective warrant, recruitment and teacher education. Journal of Teaching in Physical Education, 2, 3-16.

Leavy, A.M., McSorley, F.A., \& Bote, L.A. (2007). An examination of what metaphor construction reveals about the evolution of preservice teachers' beliefs about teaching and learning. Teaching and Teacher Education, 23, 1217-1233.

Lincoln, Y., \& Guba, E. (1985). Naturalistic inquiry. Newbury Park, CA: Sage.

Lortie, D. C. (1975). Schoolteacher: A sociological study. Chicago, IL: University of Chicago.

Morgan, P.J. (2008). Teacher perceptions of physical education in the primary school: Attitudes, values and curriculum preferences. The Physical Educator, 65(1), 46-56.

Morgan, P.J., \& Bourke, S. (2008). Non-specialist teachers' confidence to teach PE: The nature and influence of personal school experiences in PE. Physical Education and Sport Pedagogy, 13(1), 1-29.

Morgan, P.J., \& Hansen, V. (2008). Classroom teachers' perceptions of the impact of barriers to teaching physical education on the quality of physical education programs. Research Quarterly for Exercise and Sport, 79, 506-516.

National Association for Sport and Physical Education [NASPE] \& American Heart Association [AHA] (2006). 2006 Shape of the nation report: Status of physical education in the USA. Reston, VA: National Association for Sport and Physical Education.

Pajares, M. F. (1992). Teachers' beliefs and educational research: Cleaning up a messy construct. Review of Educational Research, 62, 307-332.

Pica, R. (2010). Experiences in movement \& music. Birth to age 8. United States: Wadsworth Cengage Learning. 
Placek, J. H., Dodds, P., Doolittle, S., Portman, P. A., Ratliffe, T. A., \& Pinkham, K. M. (1995). Teaching recruits' physical education backgrounds and beliefs about purposes for their subject matter. Journal of Teaching in Physical Education, 14, 246-261.

Pooley, J. C. (1975). The professional socialization of physical education students in the United States and England. International Review of Sport Sociology, 3(4), 97-108.

Randall, L.M., \& Maeda, J.K. (2003). Eastern Canadian and Hawaiian pre-service elementary generalist teachers' past experiences in elementary physical education. AVANTE, 9(2). 25-31.

Ryan, S., Bridges, S., \& Yerg, B. (2000). The influence of teacher education on teachers' beliefs about purposes of physical education. Education, 121(2), 301-304.

Stran, M., \& Curtner-Smith, M. (2009). Influence of occupational socialization on two preservices teachers' interpretation and delivery of the sport education model. Journal of Teaching Physical Education, 28, 38-53.

Weinberg, W. T., Petrillo, J.A., Doering, N., Lund, J., \& Rowe, P. J. (2000). The impact of a physical education methods class on preservice elementary teachers' attitudes toward physical education instruction. Research Quarterly for Exercise and Sport, 71 A 84-85. AAHPERD Convention Research Consortium (Abstract).

Xiang, P., Lowy, S., \& McBride, R. (2002). The impact of a field-based elementary physical education methods course on preservice classroom teachers' beliefs. Journal of Teaching in Physical Education, 21, 145-161.

Zeichner, K. M., \& Gore, J. M. (1990). Teachers' socialization. In W.R. Houston (Ed.), Handbook of Research on Teacher Education (pp. 329-348). NewYork: MacMillan. 